\title{
Bioluminescence Imaging
}

\author{
Ruxana T. Sadikot and Timothy S. Blackwell \\ Division of Allergy, Pulmonary, and Critical Care Medicine, Department of Medicine, and Departments of Cell and Developmental Biology \\ and Cancer Biology, Vanderbilt University School of Medicine; and Department of Veterans Affairs, Nashville, Tennessee
}

\begin{abstract}
Bioluminescence refers to the process of visible light emission in living organisms. Bioluminescence imaging is a powerful methodology that has been developed over the last decade as a tool for molecular imaging of small laboratory animals, enabling the study of ongoing biological processes in vivo. This form of optical imaging is low cost and noninvasive and facilitates real-time analysis of disease processes at the molecular level in living organisms. In this article, we provide a brief introduction to bioluminescence imaging technology and discuss its applications in mouse models of lung inflammation/injury, bacterial pneumonia, and tumor growth and metastasis.
\end{abstract}

Keywords: nuclear factor kappa B; lung; endotoxin; pneumonia; cancer

Molecular imaging offers many unique opportunities to study biological processes in intact organisms. Bioluminescence imaging (BLI) is based on the sensitive detection of visible light produced during enzyme (luciferase)-mediated oxidation of a molecular substrate when the enzyme is expressed in vivo as a molecular reporter. Bioluminescence at the emission wavelength firefly luciferase $(560 \mathrm{~nm})$ can be imaged as deep as several centimeters within tissue, which allows at least organ-level resolution. This technology has been applied in studies to monitor transgene expression, progression of infection, tumor growth and metastasis, transplantation, toxicology, viral infections, and gene therapy (1-21).

BLI is simple to execute and enables monitoring throughout the course of disease, allowing localization and serial quantification of biological processes without killing the experimental animal. This powerful technique can reduce the number of animals required for experimentation because multiple measurements can be made in the same animal over time, minimizing the effects of biological variation.

\section{BIOLUMINESCENCE AND BLI SYSTEMS}

Bioluminescence is appealing as an approach for in vivo optical imaging in mammalian tissues because these tissues have low intrinsic bioluminescence; therefore, images can be generated with remarkably high signal-to-noise ratios. A variety of different bioluminescent systems have been identified in nature, each requiring a specific enzyme and substrate. Although the most commonly used bioluminescent reporter for research purposes has been luciferase from the North American firefly (Photinus pyralis; FLuc), useful luciferases have also been cloned from jellyfish (Aequorea), sea pansy (Renilla; RLuc), corals (Tenilla), click

(Received in original form July 22, 2005; accepted in final form September 6, 2005) Supported by National Institutes of Health grants HL61419 and HL66196, and the U.S. Department of Veterans Affairs.

Correspondence and requests for reprints should be addressed to Timothy S. Blackwell, M.D., Vanderbilt University School of Medicine, T-1218 MCN, Nashville, TN 37232-2650. E-mail: timothy.blackwell@vanderbilt.edu

The color figures for this article are on pp. 511-512.

Proc Am Thorac Soc Vol 2. pp 537-540, 2005

DOI: 10.1513/pats.200507-067DS

Internet address: www.atsjournals.org beetle (Pyrophorus plagiophthalamus), and several bacterial species (Vibrio fischeri, V. harveyi) (22).

Firefly luciferase was cloned in 1985 (23). Three years later, an assay to measure luciferase in mammalian cell lysates was developed (24) that enabled the luciferase gene to become a useful tool for in vivo studies of gene regulation. Luciferase is an excellent marker for gene expression because of its lack of post-translational modifications and an in vivo $\mathrm{t}_{1 / 2}$ of approximately $3 \mathrm{~h}$ (25). Firefly luciferase produces photons in a reaction that requires ATP, magnesium, and a benzothiazoyl-thiazole luciferin (26). Light emission from the firefly luciferase-catalyzed luciferin reaction is broad-band (530-640 nm) and peaks at $562 \mathrm{~nm}$ (27). This emission spectrum, coupled with the optical properties of biological tissue, allows light (especially with spectral content above $600 \mathrm{~nm}$ ) to penetrate through several centimeters of tissue. Therefore, it is possible to detect light emitted from internal organs in mice that express luciferase as a reporter gene.

The sensitivity of detecting internal light sources is dependent on several factors, including the level of luciferase expression, the depth of labeled cells within the body (the distance that the photons must travel through tissue), and the sensitivity of the detection system (26). Key advances in detector technology have led to substantial improvement in sensitivity and image quality. Photons are detected by specialized charge coupled device (CCD) cameras that convert photons into electrons after striking silicon wafers. CCD cameras spatially encode the intensity of incident photons into electrical charge patterns to generate an image. For $\mathrm{BLI}$, the noise of the systems is reduced by super-cooling the CCD camera and mounting the camera in a light-tight box. These cameras are run by a computer for image acquisition and analysis. Second-generation cameras that are much smaller and can be accommodated on bench tops make the technology feasible and practical for day-to-day experimentation.

Although BLI has been used successfully in a variety of applications to obtain semiquantitative information regarding biological processes in vivo, several issues must be considered when applying this technology. Simple quantification of light emission may not provide a true representation of the biological effect studied. The luciferase reaction is a complex interaction of a variety of molecules, including ATP, oxygen, and luciferin (substrate). If ATP, oxygen, or exogenously administered luciferin is not abundantly present, light emission may not be a true representation of luciferase activity $(26,27)$. Another issue with BLI is the limited and wavelength-dependent transmission of light through animal tissues. As a general rule, there is an approximate 10-fold loss of photon intensity for each centimeter of tissue depth. Also, images are surface weighted, meaning that light sources closer to the surface of the animal appear brighter compared with deeper sources because of tissue attenuation properties (28). In addition, dynamic changes may occur in geometry (e.g., growing tumor, scar tissue) and/or the optical properties of tissues that affect light scatter or absorption and detected bioluminescence. Thus, although BLI provides a unique and powerful methodology, quantitative analysis must be approached with caution, and validation for each specific application is necessary. 


\section{APPLICATIONS OF BLI MODALITIES FOR LUNG DISEASES}

\section{Detection of Nuclear Factor-кB Activation in Reporter Mice}

Nuclear factor- $\kappa \mathrm{B}(\mathrm{NF}-\kappa \mathrm{B})$ is a ubiquitous transcription factor that plays an important role in innate immunity in the lungs by regulating lung inflammation through transcriptional regulation of a variety of proinflammatory mediators, including cytokines, chemokines, adhesion molecules, and enzymes (29). To develop a convenient method for examining NF- $\mathrm{B}$ activation in vivo, we have engineered a line of transgenic mice (referred to as HLL [HIV-LTR/Luciferase] mice) that carries the proximal 5 ' HIV-1 long terminal repeat (LTR), driving the expression of Photinus luciferase complementary DNA (30). The proximal HIV-LTR is a well-characterized, NF- $\mathrm{kB}$-responsive promoter, containing a TATA box, an enhancer region between nucleotides 82 and 103 with two NF-кB motifs, and three Sp1 boxes from nucleotides $46-78$. In primary cell culture, NF- $\mathrm{B}$ activation is required for transcriptional activity of the proximal HIV-LTR $(31,32)$. We have shown that luciferase activity in cells and tissues from these transgenic mice reflects NF-кB activation over time (30). Other investigators have generated transgenic reporter mice to study lung and systemic NF- $\mathrm{BB}$-dependent inflammatory responses $(13,33,34)$. In addition to HLL mice, we have generated reporter mice containing a synthetic $\mathrm{NF}-\kappa \mathrm{B}-$ responsive promoter with eight NF- $\kappa \mathrm{B}$ binding sites and a minimal herpesvirus thymidine kinase promoter driving a green fluorescent protein/luciferase fusion protein reporter (35). These transgenic mouse models have proven to be valuable for measuring activation of $\mathrm{NF}-\kappa \mathrm{B}$ in real time and have helped overcome the limitation of other methods of detecting NF-кB activation, such as electrophoretic mobility shift assay and Western blot analysis. In several different studies, we have shown an excellent correlation between tissue luciferase activity and bioluminescent detection of luciferase activity in HLL mice (2, 5, 36-38). BLI of luciferase activity has allowed us to measure the timing, distribution, and intensity of NF-кB activation in a variety of lung disease models involving inflammation, infection, or tumor metastasis. In addition, we have used this methodology to study the effects of gene therapy targeting the NF-кB pathway (36).

\section{Bioluminescence Detection of NF-кB Activation in Models of Lung Inflammation and Injury}

We have used HLL NF- $\mathrm{B}$ reporter mice to investigate the role of NF-кB in regulating lung inflammation and injury induced by local and systemic stimuli. Inciting stimuli have included local and systemic administration of Escherichia coli LPS and systemic inflammation induced by direct hepatic injury and pancreatitis $(5,39)$. To investigate whether parameters of NF-кB activation in vivo correlate with extent of lung injury, we used a model that results in transient lung inflammation without significant injury (a single intraperitoneal injection of LPS [2 $\mu \mathrm{g} / \mathrm{g}]$ ) compared with a model that results in sustained inflammation and progressive lung injury (delivery of LPS by intraperitoneal implantation of an ALZET osmotic pump (DuRECT Corp., Cupertino, CA) delivering LPS over $24 \mathrm{~h}$ at $8 \mu \mathrm{g} / \mathrm{h}$ ). The LPS osmotic pump model causes an extensive and sustained lung inflammatory response with neutrophilic influx, hemorrhage, and edema by $48 \mathrm{~h}$ (Everhart and coworkers, submitted for publication). Duration and intensity of NF- $\mathrm{KB}$ activity determine the severity of endotoxin-induced acute lung injury). We used BLI to detect luciferase activity as a marker of NF- $\kappa \mathrm{B}$ activation over time in both these models (Figure 1 [p. 511]). Mice were imaged at baseline and at 4, 8, 24, $48 \mathrm{~h}$ after LPS. Images were obtained $30 \mathrm{~min}$ after repeated doses of intraperitoneal luciferin $(3 \mathrm{mg})$. Both groups had significantly increased bioluminescence over the chest by $4 \mathrm{~h}$ after LPS; however, the group treated with LPS via osmotic pumps showed higher photon emission at every time point measured. The group treated with a single intraperitoneal injection of LPS returned to near baseline bioluminescence values by $48 \mathrm{~h}$, whereas the group treated with LPS pumps showed continually elevated photon emission at $48 \mathrm{~h}$, consistent with the prolonged, severe lung inflammation observed in this model. These findings demonstrate the utility of BLI for tracking the progression and resolution of biological processes in vivo.

Using another NF- $\mathrm{B}$ luciferase reporter mouse model, Carlsen and colleagues (33) showed that intravenous injection of LPS, tumor necrosis factor $\alpha$, or interleukin $1 \beta$ stimulated increased luciferase activity in the lungs and other organs as assessed by bioluminescence and tissue luciferase assays. In this study, the authors showed that increased bioluminescence could be identified by imaging organs ex vivo and that this measurement correlated well with luciferase assays in most organs. We have found a similar pattern of activation of NF-кB ex vivo after intraperitoneal and aerosolized LPS in a recent study (38).

BLI can be used to assess responses to antiinflammatory therapies. Carlsen and colleagues (33) pretreated mice with dexamethasone before intravenous injection of LPS. They found that administration of dexamethasone suppressed LPS-induced whole-mouse bioluminescence (33). In contrast to this study, when we pretreated mice with dexamethasone at $0.3,1$, or $10 \mathrm{mg} / \mathrm{kg}$ given in divided doses 24 and $1 \mathrm{~h}$ before to aerosolized LPS (2), we found that the lower doses of dexamethasone did not inhibit bioluminescence from the lungs of HLL mice. At the highest dose of dexamethasone, there was an increase in NF-кB activation and neutrophil influx in the lungs. These studies indicate that BLI can be used to follow NF- $\mathrm{B}$ activity in reporter mice in the lungs in a variety of models of lung inflammation and injury.

\section{Bioluminescence Detection of NF-кB Activation in Pseudomonas aeruginosa Pneumonia}

To investigate the role of the NF-кB pathway in host defense, we established a model of Pseudomonas aeruginosa pneumonia in HLL mice. After intratracheal administration of bacteria, we found a dose-dependent increase in chest bioluminescence (Figure 2 [p. 512]) that correlated with tissue luciferase activity and neutrophilic alveolitis at $24 \mathrm{~h}$ (37). To examine the role of reactive oxygen intermediates in NF- $\mathrm{B}$ activation and host defense and in this model, we cross-bred HLL reporter mice with mice deficient in the p47phox component of NADPH oxidase (37). After $P$. aeruginosa infection, $\mathrm{p} 47 \mathrm{phox}^{-1-}$ HLL mice showed diminished $\mathrm{NF}-\kappa \mathrm{B}$ activation in the lungs as assessed by BLI (and other parameters) and impaired bacterial clearance compared with HLL control mice. These findings showed that inflammatory signaling was inhibited by a failure to generate reactive oxygen intermediates despite an increase in bacterial burden. This study implies that production of reactive oxygen species is necessary to generate an adequate host inflammatory response through the NF- $\mathrm{B}$ pathway.

In related studies, we evaluated bacterial clearance using $P$. aeruginosa expressing the lux operon from the bacterium Photorhabdus luminescens, which was obtained from Xenogen (Alemeda, CA). By bioluminescent detection of bacterial load (which does not require exogenous luciferin injection), we confirmed that significantly more bacteria were present in the lungs of $\mathrm{p} 47 \mathrm{phox}^{-1-}$ mice compared with wild-type mice after $P$. aeruginosa infection. A variety of other studies have been performed that used bacteria expressing luciferase to investigate the pathogenesis of infections caused by Staphylococcus, Mycobacterium, E. coli, and Salmonella $(8-12,40)$. These studies have shown that the labeled bacteria can be used to track infection and may be useful to follow therapeutic interventions. Future investigations using BLI to track the bacterial burden 
and the host response to infection could lead to new insights into the pathogenesis of pneumonia or other infections.

\section{Bioluminescence Imaging to Monitor Lung Tumor Growth and Metastasis}

BLI has also been used in cancer research to track metastasis and measure tumor burden by using luciferase-expressing tumor cells. Injection of HeLa cells labeled with luciferase into the tail veins of severe combined immunodeficient mice allowed visualization of lung metastasis (15). Similarly, other studies have demonstrated that the tracking of luciferase expressing tumor cells is a powerful methodology to track and understand the pathogenesis of metastasis in vivo $(16,17)$. Detection of tumor cells from internal organs by BLI has been shown to have sensitivity at least as good as positron emission tomography (41).

We have recently used Lewis lung cancer (LLC) cells labeled with a green fluorescent protein/luciferase reporter to study a model of lung cancer metastasis after intravenous LLC cell injection. In this model, bioluminescence emission from the chest increased linearly from $24 \mathrm{~h}$ after LLC injection until harvest (Day 14), and total chest bioluminescence at the time of harvest correlated directly with number of metastases measured by lung surface tumor counts (42). We have also used BLI to investigate a novel mouse model of malignant pleural effusion after direct injection of labeled LLC cells into the pleural space of syngeneic C57B/6 mice (43). The NF- $\mathrm{B}$ pathway affects tumor progression in a mouse model of malignant pleural effusion.) In this model, luciferase activity in the pleura measured by BLI increased over time and correlated with pleural effusion volume and pleural tumor number at the time of harvest. These findings illustrate the utility of BLI as a noninvasive indicator of tumor burden in experimental models of tumor progression and metastasis.

\section{CONCLUSIONS}

Using reporter gene strategies, we and others have shown that BLI of small animals represents a powerful new methodology to detect the magnitude, spatial distribution, and timing of transgene expression in disease models. BLI has also been used to study the spatiotemporal patterns of bacterial infections using genetically engineered bioluminescent pathogens and to track tumor growth and metastasis. Bioluminescence provides a noninvasive method to monitor gene expression in vivo with an enormous potential to elucidate pathobiology of lung diseases in intact animal models.

Molecular imaging techniques represent a potentially revolutionary advance in our ability to study structural and functional relationships in biology by combining the disciplines of molecular and cellular biology and imaging technology. With BLI, the ability to track light-emitting cells in small laboratory animals has opened up a wide range of applications in biomedical research. The current combinations of reporter genes and probes should be considered "first generation" systems. Improvements can be anticipated, including multimodality imaging, that enhance the utility of available imaging systems.

Conflict of Interest Statement: Neither of the authors has a financial relationship with a commercial entity that has an interest in the subject of this manuscript.

\section{References}

1. Benaron DA, Contag PR, Contag $\mathrm{CH}$. Imaging brain structure and function, infection and gene expression in the body using light. Philos Trans $R$ Soc Lond B Biol Sci 1997;352:755-761.

2. Sadikot RT, Jansen ED, Blackwell TR, Zoia O, Yull F, Christman JW, Blackwell TS. High-dose dexamethasone accentuates nuclear factorkappa b activation in endotoxin-treated mice. Am J Respir Crit Care Med 2001;164:873-878.
3. Contag CH, Spilman SD, Contag PR, Oshiro M, Eames B, Dennery P, Stevenson DK, Benaron DA. Visualizing gene expression in living mammals using a bioluminescent reporter. Photochem Photobiol 1997;66: 523-531.

4. Contag CH, Jenkins D, Contag PR, Negrin RS. Use of reporter genes for optical measurements of neoplastic disease in vivo. Neoplasia 2000;2:41-52.

5. Sadikot RT, Wudel LJ, Jansen DE, Debelak JP, Yull FE, Christman JW, Blackwell TS, Chapman WC. Hepatic cryoablation-induced multisystem injury: bioluminescent detection of NF-kappaB activation in a transgenic mouse model. J Gastrointest Surg 2002;6:264-270.

6. Contag $\mathrm{CH}$, Bachmann $\mathrm{MH}$. Advances in in vivo bioluminescence imaging of gene expression. Annu Rev Biomed Eng 2002;4:235-260.

7. Ray P, De A, Min JJ, Tsien RY, Gambhir SS. Imaging tri-fusion multimodality reporter gene expression in living subjects. Cancer Res 2004;64:1323-1330.

8. Contag CH, Contag PR, Mullins JI, Spilman SD, Stevenson DK, Benaron DA. Photonic detection of bacterial pathogens in living hosts. Mol Microbiol 1995;18:593-603.

9. Siragusa GR, Nawotka K, Spilman SD, Contag PR, Contag CH. Realtime monitoring of Escherichia coli O157:H7 adherence to beef carcass surface tissues with a bioluminescent reporter. Appl Environ Microbiol 1999;65:1738-1745.

10. Rocchetta HL, Boylan CJ, Foley JW, Iversen PW, LeTourneau DL, McMillian CL, Contag PR, Jenkins DE, Parr TR Jr. Validation of a noninvasive, real-time imaging technology using bioluminescent Escherichia coli in the neutropenic mouse thigh model of infection. Antimicrob Agents Chemother 2001;45:129-137.

11. Francis KP, Joh D, Bellinger-Kawahara C, Hawkinson MJ, Purchio TF, Contag PR. Monitoring bioluminescent Staphylococcus aureus infections in living mice using a novel luxABCDE construct. Infect Immun 2000;68:3594-3600.

12. Francis KP, Yu J, Bellinger-Kawahara C, Joh D, Hawkinson MJ, Xiao G, Purchio TF, Caparon MG, Lipsitch M, Contag PR. Visualizing pneumococcal infections in the lungs of live mice using bioluminescent Streptococcus pneumoniae transformed with a novel gram-positive lux transposon. Infect Immun 2001;69:3350-3358.

13. Contag PR, Olomu IN, Stevenson DK, Contag CH. Bioluminescent indicators in living mammals. Nat Med 1998;4:245-247.

14. Rehemtulla A, Stegman LD, Cardozo SJ, Gupta S, Hall DE, Contag $\mathrm{CH}$, Ross BD. Rapid and quantitative assessment of cancer treatment response using in vivo bioluminescence imaging. Neoplasia 2000;2:491495.

15. Edinger M, Sweeney TJ, Tucker AA, Olomu AB, Negrin RS, Contag $\mathrm{CH}$. Noninvasive assessment of tumor cell proliferation in animal models. Neoplasia 1999;1:303-310.

16. Edinger M, Cao YA, Hornig YS, Jenkins DE, Verneris MR, Bachmann $\mathrm{MH}$, Negrin RS, Contag CH. Advancing animal models of neoplasia through in vivo bioluminescence imaging. Eur J Cancer 2002;38:21282136

17. Sweeney TJ, Mailander V, Tucker AA, Olomu AB, Zhang W, Cao Y, Negrin RS, Contag CH. Visualizing the kinetics of tumor-cell clearance in living animals. Proc Natl Acad Sci USA 1999;96:12044-12049.

18. Vooijs M, Jonkers J, Lyons S, Berns A. Noninvasive imaging of spontaneous retinoblastoma pathway-dependent tumors in mice. Cancer Res 2002;62:1862-1867.

19. Wetterwald A, van der Pluijm G, Que I, Sijmons B, Buijs J, Karperien M, Lowik CW, Gautschi E, Thalmann GN, Cecchini MG. Optical imaging of cancer metastasis to bone marrow: a mouse model of minimal residual disease. Am J Pathol 2002;160:1143-1153.

20. Koransky ML, Ip TK, Wu S, Cao Y, Berry G, Contag C, Blau H, Robbins $\mathrm{R}$. In vivo monitoring of myoblast transplantation into rat myocardium. J Heart Lung Transplant 2001;20:188-189.

21. Tang Y, Shah K, Messerli SM, Snyder E, Breakefield X, Weissleder R. In vivo tracking of neural progenitor cell migration to glioblastomas. Hum Gene Ther 2003;14:1247-1254.

22. Hastings JW. Chemistries and colors of bioluminescent reactions: a review. Gene 1996;173:5-11.

23. de Wet JR, Wood KV, Helinski DR, DeLuca M. Cloning of firefly luciferase cDNA and the expression of active luciferase in Escherichia coli. Proc Natl Acad Sci USA 1985;82:7870-7873. 
24. Nguyen VT, Morange M, Bensaude O. Firefly luciferase luminescence assays using scintillation counters for quantitation in transfected mammalian cells. Anal Biochem 1988;171:404-408.

25. Lipshutz GS, Gruber CA, Cao Y, Hardy J, Contag CH, Gaensler KM. In utero delivery of adeno-associated viral vectors: intraperitoneal gene transfer produces long-term expression. Mol Ther 2001;3:284292.

26. Wilson T, Hastings JW. Bioluminescence. Annu Rev Cell Dev Biol 1998; 14:197-230.

27. Rice BW, Cable MD, Nelson MB. In vivo imaging of light-emitting probes. J Biomed Opt 2001;6:432-440.

28. Weissleder R. A clearer vision for in vivo imaging. Nat Biotechnol 2001;19:316-317.

29. Christman JW, Sadikot RT, Blackwell TS. The role of nuclear factorkappa B in pulmonary diseases. Chest 2000;117:1482-1487.

30. Blackwell TS, Yull FE, Chen CL, Venkatakrishnan A, Blackwell TR, Hicks DJ, Lancaster LH, Christman JW, Kerr LD. Multiorgan nuclear factor kappa B activation in a transgenic mouse model of systemic inflammation. Am J Respir Crit Care Med 2000;162:1095-1101.

31. Alcami J, Lain de Lera T, Folgueira L, Pedraza MA, Jacque JM, Bachelerie F, Noriega AR, Hay RT, Harrich D, Gaynor RB. Absolute dependence on kappa B responsive elements for initiation and Tat-mediated amplification of HIV transcription in blood CD4 T lymphocytes. EMBO J 1995; $14: 1552-1560$

32. Moses AV, Ibanez C, Gaynor R, Ghazal P, Nelson JA. Differential role of long terminal repeat control elements for the regulation of basal and Tat-mediated transcription of the human immunodeficiency virus in stimulated and unstimulated primary human macrophages. J Virol 1994;68:298-307.

33. Carlsen H, Moskaug JO, Fromm SH, Blomhoff R. In vivo imaging of NF-kappa B activity. J Immunol 2002;168:1441-1446.

34. Hubbard AK, Timblin CR, Shukla A, Rincon M, Mossman BT. Activation of NF-kappaB-dependent gene expression by silica in lungs of luciferase reporter mice. Am J Physiol Lung Cell Mol Physiol 2002;282: L968-L975.

35. Blackwell TS, Han W, Everhart MB, Jansen ED, Yull FE. Imaging NFkB activation in the lungs. Mol Imaging Biol 2004;6:69.

36. Sadikot RT, Han W, Everhart MB, Zoia O, Peebles RS, Jansen ED, Yull FE, Christman JW, Blackwell TS. Selective I kappa B kinase expression in airway epithelium generates neutrophilic lung inflammation. I Immunol 2003:170:1091-1098.

37. Sadikot RT, Zeng H, Yull FE, Li B, Cheng DS, Kernodle DS, Jansen ED, Contag CH, Segal BH, Holland SM, et al. p47phox deficiency impairs NF-kappa B activation and host defense in Pseudomonas pneumonia. J Immunol 2004;172:1801-1808.

38. Yull FE, Han W, Jansen ED, Everhart MB, Sadikot RT, Christman JW, Blackwell TS. Bioluminescent detection of endotoxin effects on HIV-1 LTR-driven transcription in vivo. J Histochem Cytochem 2003;51:741749.

39. Gray KD, Simovic MO, Chapman WC, Blackwell TS, Christman JW, May AK, Parman KS, Stain SC. Endotoxin potentiates lung injury in cerulein-induced pancreatitis. Am J Surg 2003;186:526-530.

40. Hickey MJ, Arain TM, Shawar RM, Humble DJ, Langhorne MH, Morgenroth JN, Stover CK. Luciferase in vivo expression technology: use of recombinant mycobacterial reporter strains to evaluate antimycobacterial activity in mice. Antimicrob Agents Chemother 1996;40: 400-407.

41. Iyer M, Berenji M, Templeton NS, Gambhir SS. Noninvasive imaging of cationic lipid-mediated delivery of optical and PET reporter genes in living mice. Mol Ther 2002;6:555-562.

42. Stathopoulos GT, Sherrill T, Yull FE, Fingleton B, Blackwell TS. Nuclear factor-kB (NF-kB)-mediated lung inflammation enhances lung cancer metastasis in mice. Proc Am Thorac Soc 2005;2:A56.

43. Stathopoulos GT, Zhu Z, Everhart MB, Kalomenidis I, Lawson WF, Bilaceroglu S, Peterson TE, Mitchell D, Yull FE, Light RW, et al. Nuclear factor- $\mathrm{\kappa} B$ affects tumor progression in a mouse model of malignant pleural effusion. Am J Respir Cell Mol Biol [online ahead of print] 6 Oct 2005; DOI: 10.1164/rccm.200503-644OC. Most recent version available from http://dx.doi.org/10.1164/rccm.200305-644OC 